\title{
HUBUNGAN ANTARA GAYA KEPEMIMPINAN DENGAN AKUNTABILITAS KEPALA MADRASAH ALIYAH NEGERI DI PROVINSI JAMBI
}

\author{
Sugeng Kurniawan \\ Institut Agama Islam Yasni Bungo \\ Email: sugengkurniawan@iaiyasnibungo.ac.id \\ Muzakki \\ Institut Agama Islam Yasni Bungo \\ Email: muzakki@iaiyasnibungo.ac.id
}

\begin{abstract}
This study aims to determine the relationship between Leadership Style with Accountability the Head of the State Madrasah Aliyah in Jambi Province. The usefulness of this research is to enrich the scientific paradigm in the field of Islamic Education Management, especially the study of organizational behavior. This research is a quantitative research with survey method. The population of this study were State Madrasah Aliyah (MAN) in Jambi Province with a unit sample of 124 teachers taken using the area sampling technique. The research instrument was a questionnaire with a Likert scale. The hypothesis in this study are: 1) there is a relationship between leadership style and accountability of the head of MAN. Hypothesis testing using correlation analysis begins with an analysis of the test requirements which include normality test, homogeneity test, and linearity regression test at a significant level $\alpha=0.05$. The results of the analysis show that: 1 ) the direct relationship between leadership style and accountability of the head of the State Madrasah Aliyah with a correlation coefficient of 0.35 . The conclusion of this study is leadership style, related to the accountability of the head of the State Madrasah Aliyah. The implication is that the better the leadership style made by the headmaster, the better the accountability.
\end{abstract}

Keywords: leadership style, and accountability of madrasah principals.

\begin{abstract}
Abstrak
Penelitian ini bertujuan untuk mengetahui hubungan antara gaya kepemimpinan, dengan akuntabilitas kepala Madrasah Aliyah Negeri di Provinsi Jambi. Kegunaan penelitian ini untuk memperkaya paradigma keilmuan di bidang Manajemen Pendidikan Islam khususnya kajian perilaku organisasi. Penelitian ini merupakan penelitian kuantitatif dengan metode survei. Populasi penelitian ini adalah Kepala
\end{abstract}

Nur El-Islam, Volume 7, Nomor 1, April 2020 
Madrasah Aliyah Negeri (MAN) di Provinsi Jambi. Sampel penelitian sebanyak 3 Kepala Madrasah yang diambil dengan menggunakan teknik proporsional random sampling. Untuk meneliti kepala madrasah tersebut diperlukan unit sampel 124 responden. Instrumen penelitian adalah angket dengan skala Likert. Hipotesis dalam penelitian ini adalah terdapat hubungan antara gaya kepemimpinan dengan akuntabilitas kepala MAN. Pengujian hipotesis menggunakan analisis korelasi diawali dengan uji persayaratan analisis yang meliputi uji normalitas, uji homogenitas, dan uji linearitas regresi pada taraf signifikan $\alpha=0,05$. Hasil analisis menunjukkan bahwa hubungan langsung antara gaya kepemimpinan dengan akuntabilitas kepala Madrasah Aliyah Negeri dengan koefisien korelasi sebesar 0,35. Kesimpulan penelitian ini adalah gaya kepemimpinan berhubungan dengan akuntabilitas kepala Madrasah Aliyah Negeri. Implikasinya semakin baik gaya kepemimpinan yang dilakukan kepala madrasah maka akan semakin baik akuntabilitasnya.

Kata kunci: gaya kepemimpinan, dan akuntabilitas kepala madrasah.

\section{PENDAHULUAN}

Semangat reformasi pendayagunaan aparatur negara, menuntut kesungguhan pemerintah menanggulangi korupsi, kolusi, dan nepotisme agar tercipta pemerintahan yang bersih. Jika dicermati, upaya pemerintah untuk menyelenggarakan pemerintah yang baik sudah terwujud dengan di keluarkannya Undang-undang Nomor 28 Tahun 1998 tentang penyelenggaraan negara yang bersih dan bebas Korupsi, Kolusi, dan Nepotisme (KKN). Untuk mewujudkan amanah undang-undang tersebut, maka dikeluarkanlah Undang-undang Nomor 17 tahun 2003 tentang keuangan negara. ${ }^{1}$

Konsep dasar akuntabilitas terletak pada klasifikasi responsibilitas menajerial tiap tingkatan organisasi pemerintah. Masing-masing individu bertanggung jawab atas setiap kegiatan bagiannya. $^{2}$ (Departemen Agama RI, Akuntabilitas, 2006) Allah SWT berfirman dalam Q.S. Al-Isra' (17):34. ${ }^{3}$

Sebagaimana terdapat dalam tafsir Ibnu Katsir, ayat di atas menjelaskan bahwa janji yang telah kamu adakan dengan orang lain

${ }^{1}$ Agus Wibowo, Akuntabilitas Pendidikan; Upaya Meningkatkan Mutu dan Citra Sekolah (Yogyakarta: Pustaka Pelajar, 2013), h. 33-35.

${ }^{2}$ Departemen Agama RI, Akuntabilitas dan Good Governance (Jakarta: Sekretariat Jenderal Biro organisasi dan tatalaksana, 2006), h. 1.

${ }^{3}$ Departemen Agama RI, Mushaf Al-Qur'an dan Terjemahnya (Jakarta: Al-Huda, 2005), h. 286. 
dan transaksi-transaksi yang telah di tanda tangani bersama mereka dalam muamalahmu. Karena sesungguhnya janji dan transaksi itu, masing-masing dari keduanya akan menuntut pelakunya untuk memenuhinya, dan pelakunya akan dimintai pertanggungjawabannya. ${ }^{4}$

Kementerian Agama menetapkan petunjuk pelaksaan akuntabilitas, dengan Keputusan Menteri Agama Nomor 489 Tahun 2000 yang diperbaharui dengan Keputusan Menteri Agama Nomor 507 Tahun 2003 yang selanjutnya disempurnakan kembali dengan Peraturan Menteri Agama Nomor 21 Tahun 2006 dan diinstruksikan kepada semua unit kerja, satuan organisasi/kerja Kementerian Agama se-Indonesia untuk melaksanakannya sesuai dengan tugas dan fungsi masing-masing. ${ }^{5}$

Akuntabilitas pendidikan khususnya di sekolah telah diatur dalam Undang-undang Republik Indonesia Nomor 20 Tahun 2003 tentang Sistem Pendidikan Nasional (Sisdiknas) pada pasal 48 tentang pengelolaan dana pendidikan. Pasal 48 ayat 1 menjelaskan bahwa pengelolaan dana pendidikan berdasarkan pada prinsip keadilan, efesien, transparansi dan akuntabilitas publik. ${ }^{6}$

Ghizelli dan Stodgill mengemukakan sifat ideal seorang pemimpin adalah intepegent, supervisory ability (kemampuan mengawasi), inisiatif, self assurance (jaminan diri) dan personality (kepribadian). Thomas W. Harell mengemukakan dengan sifat sebagai berikut: strong will (keinginan yang kuat), extroversion (menerima pendapat orang lain), power need (butuh kekuatan) dan achieve need (memiliki tujuan). ${ }^{7}$

Untuk mencapai kesuksesan dalam melaksanakan tugas-tugas organisasi/lembaga dan interaksi sosial, seorang pemimpin dituntut

${ }^{4}$ Ibn Katsir, Tafsir Ibnu Katsir, terjemahan Abdullah bin Muhammad bin Abdurrahman bin Ishaq al-Sheikh (Bogor: Pustaka Imam Syafi'i), h. 163-164.

${ }^{5}$ Departemen Agama RI, Akuntabilitas dan Good Governance, h.2.

${ }^{6}$ Tim Redaksi FOKUSMEDIA, Himpunan Peraturan Perundang-undangan Tentang Sistem Pendidikan Nasional (Bandung: FOKUSMEDIA, 2006), h. 115-116.

${ }^{7}$ Fatah Syukur, Manajemen Pendidikan Berbasis pada Madrasah, (Semarang: Pustaka Rizki Putra, 2011), h. 27. 
memiliki sifat-sifat yang ideal. Sifat yang ideal tersebut telah tercermin pada diri Rasulullah SAW, karena beliaulah pemimpin yang mampu menerapkan kepemimpinan secara arif dan demokratis. Di mana rasulullah SAW merupakan suri tauladan yang baik yang kepribadiannya diliputi oleh sifat-sifat yang baik, yaitu: siddiq (jujur), amanah (terpercaya), tabligh (menyampaikan) dan fatanah (cerdas/pandai). Oleh karena itu hendaknya pemimpin pendidikan Islam selalu mencontoh perilaku Rasulullah SAW yang tercermin dalam sifat-sifatnya. ${ }^{8}$

Berdasarkan hasil penelitian awal yang dilakukan peneliti, terkait data tentang akuntabilitas kepala Madrasah Aliyah Negeri di provinsi Jambi, dan didukung dari beberapa indikasi Data Pokok Pendidikan (Dapodik) pada portal sudung belaja diperoleh informasi bahwa kondisi objektif mutu pendidikan di Provinsi Jambi pada jenjang pendidikan menengah masih memiliki banyak kelemahan yang harus segera diperbaiki dan ditingkatkan secara sistemik dan sistimatis. Oleh karena itu dibutuhkan komitmen tinggi dari pemerintah dan pemerintah daerah dan semua stakeholder yang direfleksikan melalui kerja keras untuk mewujudkan pendidikan bermutu. Beberapa hasil rekam data berikut menjelaskan kondisi pendidikan Jambi saat ini. ${ }^{9}$

Adapun permasalahan yang berkaitan dengan akuntabilitas kepala Madrasah Aliyah Negeri dapat diidentifikasi sebagai berikut:

1. Sebagian besar mutu satuan pendidikan (sekolah) belum memenuhi Standar Nasional Pendidikan. Dari 5.296 jumlah sekolah di Provinsi Jambi, 3.786 (71,49\%) sekolah belum memenuhi standar nasional pendidikan, dan yang belum terakreditasi berjumlah 1.952 sekolah (36,86\%).

2. Masih lemahnya sistem manajemen SDM guru dan tenaga kependidikan, terutama dalam pola rekruitmen, seleksi, penempatan dan pendistribusian, pembinaan karier, kesejahteraan

8 Nur Efendi, Islamic Educational Leadership; Memahami Integrasi Konsep Kepemimpinan di Lembaga Pendidikan Islam, (Yogyakarta: Kalimedia, 2015), h. 33-36.

${ }^{9}$ existing condition, (ttp://disdik.jambiprov.go.id/web/tampil/opini/detail/3). 
dan remunerasi, serta pemberhentian tenaga guru, kepala sekolah, pengawas sekolah dan tenaga kependidikan lainnya yang sering keliru.

3. Kualifikasi dan kompetensi kepala sekolah belum memadai.

4. Masih tingginya ketidakpuasan masyarakat terhadap karakter, moralitas atau etika lulusan sekolah dan layanan pendidikan.

5. Sekolah belum mampu melakukan evaluasi diri sekolah secara berkesinambungan.

Fenomena di atas membawa dampak begitu pentingnya akuntabilitas bagi kepala Madrasah Aliyah Negeri di Provinsi Jambi. Hal ini sesuai dengan Keputusan Menteri Agama Republik Indonesia Nomor 172 Tahun 2014 tentang petunjuk pelaksanaan penyusunan penetapan kinerja dan pelaporan akuntabilitas kinerja di lingkungan Kementerian Agama. Oleh karena itu dalam ragka meneliti akuntabilitas tersebut maka diperlukan suatu studi tentang variabel yang mempunyai korelasi. Dalam hal ini peneliti akan meneliti korelasi variabel gaya kepemimpinan dengan akuntabilitas kepala Madrasah Aliyah Negeri.

\section{Akuntabilitas Kepala Madrasah}

Secara terminologi accountability dari akar kata "account", artinya laporan. Dalam Al-Qur'an, account adalah hisab (perhitungan). Kata hisab dapat ditemukan pada beberapa surat dan ayat Al-Qur'an, Allah SWT berfirman dalam Q.S. An-Nahl/16:93. ${ }^{10}$

Akuntabilitas secara umum berkaitan dengan kewajiban seseorang untuk "account" kepada Allah SWT dalam segala hal yang berkaitan dengan usaha manusia. Segala sumber daya yang tersedia untuk manusia ini merupakan bentuk sebuah kepercayaan, manusia menggunakan apa yang dipercayakan kepada mereka (manusia) didasarkan pada ketentuan-ketentuan syari'ah dan keberhasilan individu di akhirat bergantung pada kinerja manusia di dunia.

${ }^{10}$ Kementerian Agama RI, Qur'an Asy-Syifaa' Hafalan Terjemah dan Tajwid Berwarna Metode Tikrar, (Bandung: Sigma Examedia Arkaleema, 2018), h. 277. 
Menurut Donald R. Mc.Adams “Accountability is holding people responsible for meeting standards. Accountability is at the core of standards-based school reform. Without accountability, standards are not really standards, but rather just goals". ${ }^{11}$

Berdasarkan uraian di atas dapat disimpulkan bahwa akuntabilitas kepala madrasah adalah kewajiban kepala madrasah sebagai manajer atau pemimpin untuk memberikan pertanggungjawaban atau menjawab dan menerangkan kinerja yang telah dilakukan kepada pihak yang memiliki hak atau berkewajiban untuk meminta pertanggungjawaban. Berdasarkan kesimpulan tersebut maka diperoleh indikator-indikator sebagai berikut: (1) patuh terhadap hukum, (2) melayani dengan responsif (3), menghindari korupsi, kolusi dan nepotisme, (4) memilih alternatif program yang memberikan hasil optimal, (5) mempertanggung jawabkan kebijakan yang telah diambil.

\section{Gaya Kepemimpinan}

Kepemimpinan atau leadership merupakan seni dan keterampilan orang dalam memanfaatkan kekuasaannya untuk mempengaruhi orang lain agar melaksanakan aktifitas tertentu yang diarahkan pada tujuan yang telah ditetapkan. Memimpin yaitu mengerjakan niat demi tujuan tertentu. Orang yang dipimpin adalah diperintah, dipengaruhi dan diatur oleh ketentuan yang berlaku secara formal, nonformal dan informal. ${ }^{12}$

Menurut Ibn Katsir di dalam tafsirnya al-Qur'an al-'Adim, sikap lemah lembut yang dimiliki oleh nabi Muhammad SAW itu tiada lain disebabkan karena rahmat Allah yang dianugrahkan kepadanya, sehingga beliau bersikap lemah lembut terhadap mereka. Demikian juga Al-Hasan Al-Basri mengatakan bahwa begitulah akhlak nabi Muhammad SAW yang diutus oleh Allah. Kemudian ayat selanjutnya mengatakan: "dan jikalau kamu bersikap keras dan berhati kasar

${ }^{11}$ Mc. Adams, D., et.al. Urban school district accountability systems. (U.S: Center for Reform of School Systems under a grant from the U.S. Department of Education, 2003), h. 2 .

${ }^{12}$ Saefullah, Manajemen Pendidikan Islam (Bandung: Pustaka Setia, 2012), h. 139. 
tentulah mereka akan menjauh darimu”. Artinya adalah sekiranya kamu kasar dalam berbicara dan berkeras hati dalam menghadapi mereka, niscaya mereka bubar darimu dan meninggalkanmu. ${ }^{13}$

Bahkan dalam Al-Qur'an juga ditegaskan bahwa setiap manusia bertanggungjawab memakmurkan bumi. Di sisi lain kepemimpinan dalam Islam dimaknai sebagai kemampuan melaksanakan perintah dan meninggalkan larangan Allah, baik bersama maupun perorangan ${ }^{14}$ (Saefullah, 2012). Sebagaimana firman Allah SWT. dalam Q.S. Ali Imran/3:159. ${ }^{15}$

Rensis Likert (pendukung manajemen paternalistik) melakukan penelitian di University of Michingan. Likert melakukan penelitian ini untuk menentukan pemimpin efektif atau tidak efektif. Hasilnya adalah perilaku pemimpin dikelompokkan menjadi dua kelompok yaitu task oriented behavior (perilaku berorientasi pada tugas) dan relationship-oriented behavior (perilaku berorientasi pada hubungan). Likert memendang bahwa manajemen yang efektif sangat berorientasi pada bawahan yang bertanggung jawab atas komunikasi untuk tetap menjaga agar semua orang bekerja sebagai suatu unit. ${ }^{16}$

Sedangkan penelitian yang dilakukan oleh Blake dan Mouton yang dikenal dengan model Leadership Grid, menjelaskan tentang bagaimana pemimpin membantu organisasi untuk mencapai tujuan yakni melalui dua faktor, yaitu perhatian pada produksi dan perhatian pada orang. Walaupun kepemimpinan ini digambarkan sebagai orientasi kepemimpinan dalam model, namun sangat mirip dengan kepemimpinan yang berorientasi pada perilaku dan hubungan. Dapat dijelaskan bahwa yang dimaksud dengan perhatian pada produk adalah bahwa pemimpin peduli dengan pencapaian tugas organisasi. Sedangkan yang dimaksud dengan perhatian pada orang adalah

13 Imam Abdul Fida Isma'il Ibnu Kasit Ad-Dimasyqi, Tafsir Ibnu Katsir, terjemahan. Bahrun Abu Bakar (Bandung: Sinar Baru Algesindo, 2009), h. 244-251.

${ }^{14}$ Veithzal Rivai, Bachtiar dan Boy Rafly Amar, Pemimpin dan kepemimpinan dalam Organisasi (Jakarta: Raja Grafindo Persada, 2013), h. 62.

${ }^{15}$ Kementerian Agama RI, Qur'an Asy-Syifaa', h. 71.

${ }^{16}$ Wirawan, Kepemimpinan: Teori, Psikologi, Perilaku Organisasi, Aplikasi dan Penelitian (Jakarta: Raja Grafindo Persada, 2013), h. 354-355. 
pemimpin mampu menghadapi orang-orang dalam organisasi dalam rangka mencapai tujuan. Model ini menggambarkan lima gaya kepemimpinan utama yaitu: otoritas-kepatuhan $(9,1)$, manajemen country-club (1,9), manajemen yang lemah $(1,1)$ manajemen di persimpangan jalan $(5,5)$, dan manajemen tim $(9,9) .{ }^{17}$

Gaya kepemimpinan dapat diartikan sebagai sesuatu pola yang dilakukan oleh para pemimpin, yaitu proses di mana para pemimpin menggunakan pengaruhnya untuk memperjelas tujuan organisasi bagi para pegawai, bawahan, atau yang dipimpinnnya, memotivasi mereka untuk mencapai tujuan tersebut, serta membantu menciptakan suatu budaya produktif dalam organisasi. ${ }^{18}$

Berdasarkan uraian di atas dapat disimpulkan bahwa gaya kepemimpinan adalah bentuk perilaku pemimpin dalam memimpin atau mempengaruhi bawahannya untuk mencapai tujuan yang telah ditetapkan, agar tujuan tersebut dapat dijadikan sebagai tujuan bersama. Berdasarkan kesimpulan tersebut maka diperoleh indikatorindikator sebagai berikut: (1) memberikan instruksi; (2) mengadakan konsultasi; (3) memiliki partisipasi; (4) mendelegasikan.

\section{METODOLOGI PENELITIAN}

Penelitian ini merupakan penelitian kuantitatif dengan rancangan penelitian survei dengan teknik korelasional. Konstelasi penelitian hubungan antara variabel bebas dengan variabel terikat dapat dilihat pada gambar berikut ini:

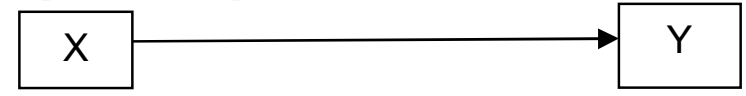

Keterangan:

Y : Akuntabilitas Kepala Madrasah Aliyah Negeri

$\mathrm{X}$ : Gaya Kepemimpinan

Populasi dalam penelitian ini adalah Kepala Madrasah Aliayah Negeri (MAN) di provinsi Jambi yang tersebar dalam 11 wilayah

${ }^{17}$ Peter G. Northouse, Kepemimpinan; Teori dan Praktik. Edisi Keenam, terj. Ati Cahayani, (Jakarta: Indeks, 2013), h. 76.

${ }^{18}$ Suwatno dan Donni Juni Priansa, Manajemen SDM dalam Organisasi Publikasi dan Bisnis, (Bandung: Alfabeta, 2013), h. 140-141. 
kabupaten dan kota $^{19}$. Adapun populasi yang dijadikan target dalam penelitian ini adalah Kepala MAN Model Jambi, MAN 1 Bungo dan MAN 1 Sarolangun. Hal ini dipilih berdasarkan sebaran wilayah yang telah ditetapkan peneliti.

Teknik penentuan sampel dalam penelitian ini ditentukan dengan teknik proporsional random sampling. Dengan teknik proporsional random sampling maka ditetapkan yang menjadi sampel penelitian ini adalah Kepala MAN Model Jambi, MAN 1 Bungo dan MAN 1 Sarolangun. Unit sampel yang dipilih peneliti adalah guru yang berjumlah sebanyak 154 orang guru sebagai responden. Dari unit sampel yang diperoleh tidak keseluruhan digunakan sebagai sampel penelitian, tetapi ada yang digunakan sebagai sampel uji coba validitas dan reliabilitas instrumen penelitian. Sampel uji coba instrumen penelitian melibatkan 30 orang guru sebagai respoden, dan selebihnya ditetapkan sebagai sampel penelitian, yaitu 124 orang guru sebagai responden.

Teknik pengumpulan data yang digunakan dalam penelitian ini adalah dengan angket atau kuesioner. Angket atau kuesioner merupakan teknik pengumpulan data yang dilakukan dengan cara memberi seperangkat pertanyaan atau pernyataan tertulis kepada responden untuk dijawab, dengan tujuan untuk memperoleh informasi yang lengkap ${ }^{20}$. Untuk memperoleh data dalam penelitian ini menggunakan alat ukur skala Likert. ${ }^{21}$ Instrumen variabel dalam penelitian ini menggunakan pilihan: Sangat Setuju (SS), Setuju (S), Netral (N), Tidak Setuju (TS), Sangat Tidak Setuju (STS). ${ }^{22}$

Teknik analisis data dalam penelitian ini menggunakan tahapan analisis deskriptif, pengujian persyaratan analisis, dan analisis

19 Kasi Kelembagaan dan Sistem Informasi Madrasah Bidang pendidikan Madrasah, Laporan Data Madrasah (Jambi: Kanwil Kementerian Agama Provinsi Jambi, 2013), h. 25-31.

${ }^{20}$ Riduwan, Skala Pengukuran Variabel-variabel Penelitian (Bandung: Alfabeta, 2013), h. 25.

${ }^{21}$ Tukiran Taniredja dan Hidayati Mustafidah, Penelitian Kuantitatif (Sebuah Pngantar) (Bandung: Alfabeta, 2012), h. 45.

${ }^{22}$ Riduwan, Skala Pengukuran, h. 15. 
infetensial. Adapun hipotesis statistik dan hipotesis penelitian adalah sebagai berikut:

$\mathrm{H}_{\mathrm{o}}: \rho \mathrm{y}_{1}=0$ artinya terdapat hubungan positif dan signifikan antara gaya kepemimpinan dengan akuntabilitas kepala Madrasah Aliyah Negeri.

$\mathrm{H}_{\mathrm{a}}: \rho \mathrm{y}_{1} \neq 0$ artinya tidak terdapat hubungan positif dan signifikan antara gaya kepemimpinan dengan akuntabilitas kepala Madrasah Aliyah Negeri.

\section{PEMBAHASAN}

Deskripsi data penelitian yang disajikan dalam bagian ini meliputi variabel penelitian gaya kepemimpinan dan akuntabilitas kepala madrasah. Data yang dideskripsikan adalah gejala pusat (central tendency) yang meliputi: skor tertinggi, skor terendah, rata-rata (mean), nilai yang sering muncul pada jawaban responden (modus), nilai tengah (median), simpangan baku (standar deviasi) serta varians sampel. Selain ukuran gejala pusat dan penyebaran data digunakan juga tabel distribusi frekuensi dan grafik histogram. Pengolahan data dilakukan secara manual dan SPSS Versi 23.

Tabel Rekapitulasi Perhitungan Statistik Deskriptif

\begin{tabular}{|c|c|c|c|}
\hline & $\begin{array}{l}\text { X_Gaya } \\
\text { Kepemiminan }\end{array}$ & $\begin{array}{l}\text { Y_Akuntabilitas } \\
\text { Madrasah }\end{array}$ & Kepala \\
\hline Valid & 124 & 124 & \\
\hline Missing & 0 & 0 & \\
\hline Mean & 142.48 & 132.45 & \\
\hline Median & 142.11 & 132.50 & \\
\hline Mode & 138.92 & 129.45 & \\
\hline Std. & 6.67 & 6.36 & \\
\hline Range & 35 & 29 & \\
\hline Minimum & 123 & 117 & \\
\hline Maximum & 158 & 146 & \\
\hline Sum & 17667 & 16424 & \\
\hline
\end{tabular}




\section{Pengujian Persyaratan Analisis}

\section{Uji Normalitas}

Pengujian normalitas data dengan Chi-Kuadrat $\left(\chi^{2}\right)$ dilakukan dengan cara membandingkan kurve normal yang terbentuk dari data yang telah terkumpul (B) dengan kurva normal baku/standard (A). Jadi membandingkan antara (B:A). Bila B tidak berbeda secara signifikan dengan A, maka B merupakan data yang berdistribusi normal.

Kurva normal baku yang luasnya mendekati 100\% itu dibagii menjadi 6 bidang berdasarkan simpangan bakunya, yaitu tiga bidang di bawah rata-rata (mean) dan tiga bidang di atas rata-rata. Luas 6 bidang dalam kurva normal adalah: 2,27\%; 13,53\%; 34,13\%; 34,13\%; $13,53 \% ; 2,27 \%{ }^{23}$

\section{Uji Normalitas Variabel Akuntabilitas Kepala Madrasah Aliyah Negeri (Y)}

Uji normalitas dilakukan dengan menggunakan Uji Chi Kuadrat yang diawali dengan menentukan taraf signifikansi $\alpha=0,05$. Untuk menguji hipotesis, $\mathrm{H}_{\mathrm{o}}$ : berarti data berdistribusi normal atau $\mathrm{H}_{a}$ : berarti data berdistribusi tidak normal, dapat diketahui dengan membandingkan nilai $x^{2}$ hitung dengan $x^{2}$ tabel dengan pertimbangan:

Jika $X^{2}$ hitung $<X^{2}$ tabel, maka distribusi data normal.

Jika $x^{2}$ hitung $>x^{2}$ tabel, maka distribusi tidak normal.

Tabel Pengujian Normalitas Data dengan Chi Kuadrat Variabel Kinerja Akuntabilitas Kepala Madrasah (Y)

\begin{tabular}{|c|c|c|c|c|c|c|}
\hline No & Interval & $\mathrm{F}_{\mathrm{o}}$ & $\mathrm{F}_{\mathrm{h}}$ & $\mathrm{F}_{\mathrm{o}}-\mathrm{F}_{\mathrm{h}}$ & $\left(\mathrm{F}_{\mathrm{o}}-\mathrm{F}_{\mathrm{h}}\right)^{2}$ & $\frac{\left(f_{o}-f_{e}\right)^{2}}{f_{h}}$ \\
\hline 1 & $117-121$ & 3 & 3 & 0 & 0 & 0.04 \\
\hline 2 & $122-126$ & 16 & 17 & -1 & 1 & 0.04 \\
\hline 3 & $127-131$ & 43 & 42 & 1 & 0 & 0.01 \\
\hline 4 & $132-136$ & 43 & 42 & 1 & 0 & 0.01 \\
\hline
\end{tabular}

${ }^{23}$ Syofian Siregar, Metode Penelitian Kuantitatif: Dilengkapi dengan Perhitungan Manual \& SPSS (Jakarta: Kencana, 2013), h. 137 \& 517. 
Hubungan Antara Gaya ...

\begin{tabular}{|c|c|c|c|c|c|c|}
5 & $137-141$ & 16 & 17 & -1 & 1 & 0.04 \\
\hline 6 & $142-146$ & 3 & 3 & 0 & 0 & 0.04 \\
\hline & Jumlah & 124 & 124 & & $\chi_{\text {hitung }}^{2}$ & 0.17 \\
\hline & & & & & $\chi_{\text {tabel }}^{2}$ & 11,070 \\
\hline
\end{tabular}

Membandingkan harga Chi Kuadrat hitung $=0,17$. Selanjutnya harga ini dibandingkaan dengan chi kuadrat dengan dk (derajat kebebasan $6-1=5$. Berdasarkan tabel Chi Kuadrat yang ada pada tabel dapat diketahui bahwa bila $\mathrm{dk}=5$ dan kesalahan yang ditetapkan $=5 \%$, maka harga chi kuadrat tabel $=11,070$.

Karena Harga $\left(\chi_{\text {hitung }}^{2}\right)=0,17<$ tabel $\left(\chi_{\text {tabel }}^{2}\right)=11,070$, maka distribusi data nilai statistik 124 sampel tersebut dapat dinyatakan normal.

\section{Uji Normalitas Variabel Gaya Kepemimpinan (X)}

Uji normalitas dilakukan dengan menggunakan Uji Chi Kuadrat yang diawali dengan menentukan taraf signifikansi $\alpha=0,05$. Untuk menguji hipotesis, $\mathrm{H}_{\mathrm{o}}$ : berarti data berdistribusi normal atau $\mathrm{H}_{\mathrm{a}}$ : berarti data berdistribusi tidak normal, dapat diketahui dengan membandingkan nilai $x^{2}$ hitung dengan $x^{2}$ tabel dengan pertimbangan: Jika $x^{2}$ hitung $<X^{2}$ tabel, maka distribusi data normal. Jika $x^{2}$ hitung $>X^{2}$ tabel, maka distribusi tidak normal.

Tabel Pengujian Normalitas Data dengan Chi Kuadrat Variabel Gaya Kepemimpinan (X)

\begin{tabular}{|c|c|c|c|c|c|c|}
\hline No & Interval & $\mathrm{F}_{\mathrm{o}}$ & $\mathrm{F}_{\mathrm{h}}$ & $\mathrm{F}_{\mathrm{o}}-\mathrm{F}_{\mathrm{h}}$ & $\left(\mathrm{F}_{\mathrm{o}}-\mathrm{F}_{\mathrm{h}}\right)^{2}$ & $\frac{\left(f_{o}-f_{e}\right)^{2}}{f_{h}}$ \\
\hline 1 & $123-128$ & 2 & 3 & -1 & 2 & 1.00 \\
\hline 2 & $129-134$ & 13 & 17 & -4 & 14 & 0.85 \\
\hline 3 & $135-140$ & 36 & 42 & -6 & 16 & 0.38 \\
\hline 4 & $141-146$ & 51 & 42 & 9 & 75 & 1.78 \\
\hline 5 & $147-152$ & 16 & 17 & -1 & 1 & 0.04 \\
\hline
\end{tabular}




\begin{tabular}{|c|c|c|c|c|c|c|}
6 & $153-158$ & 6 & 3 & 3 & 1 & 0.50 \\
\hline & Jumlah & 124 & 124 & & $\chi_{\text {hitung }}^{2}$ & 4.54 \\
\hline & & & & & $\chi_{\text {tabel }}^{2}$ & 11,070 \\
\hline
\end{tabular}

Membandingkan harga Chi Kuadrat hitung $=4,54$. Selanjutnya harga ini dibandingkaan dengan chi kuadrat dengan dk (deraajat kebebasan $6-1=5$. Berdasarkan tabel Chi Kuadrat yang ada pada tabel dapat diketahui bahwa bila $\mathrm{dk}=5$ dan kesalahan yang ditetapkan $=5 \%$, maka harga chi kuadrat tabel $=11.070$.

Karena Harga $\left(\chi_{\text {hitung }}^{2}\right)=4,54<$ tabel $\left(\chi_{\text {tabel }}^{2}\right)=11,070$, maka distribusi data nilai statistik 124 sampel tersebut dapat dinyatakan normal.

Uji Homogenitas Y dengan X

\begin{tabular}{|c|c|c|c|c|c|c|c|}
\hline NO & $\mathbf{X}$ & $\mathrm{Y}$ & $\begin{array}{l}\mathrm{d} \\
\mathrm{k}\end{array}$ & $\mathrm{S}_{\mathrm{i}}^{2}$ & $\operatorname{dk}\left(\mathrm{S}_{\mathrm{i}}^{2}\right)$ & $\log . S_{i}^{2}$ & dk.(Log. $S_{\mathrm{i}}^{2}$ \\
\hline $\begin{array}{c}\mathrm{Jm} \\
1\end{array}$ & $\begin{array}{c}1766 \\
7\end{array}$ & $\begin{array}{c}1642 \\
4\end{array}$ & 90 & $\begin{array}{c}551.951 \\
6\end{array}$ & $\begin{array}{c}27.3091 \\
9\end{array}$ & $\begin{array}{c}1754.29 \\
4\end{array}$ & 102.7036 \\
\hline
\end{tabular}

\begin{tabular}{|l|r|}
\hline Varian Gabungan & 19,49 \\
\hline Harga Satuan B & 116,08 \\
\hline Harga Chi Kuadrat & 30,80 \\
\hline Chi Tabel $(0.95: 90)$ & 113,1450 \\
\hline Final Result & Data Homogen \\
\hline
\end{tabular}

Hasil perhitungan untuk pengujian homogenitas varians variabel Akuntabilitas Kepala Madrasah (Y) atas Gaya Kepemimpinan (X) diperoleh $\chi_{\text {hitung }}^{2}=30,80$ sementara pada tabel dengan $\mathrm{dk}=90$ pada $\alpha$ $=0,05$ diperoleh $\chi_{\text {tabel }}^{2}=113,1450$ Karena $\chi_{\text {hitung }}^{2}<\chi_{\text {tabel }}^{2}$, maka $\mathrm{H}_{0}$ diterima yang berarti varians Akuntabilitas Kepala Madrasah (Y) atas Gaya Kepemimpinan (X) adalah homogen. 
Uji linearitas regresi gaya kepemimpinan (X) dengan akuntabilitas kepala Madrasah Aliyah Negeri (Y)

Uji terakhir yang diperlukan sebelum dilakukan analisis adalah uji linearitas regresi. Uji ini dimaksudkan untuk mengetahui bahwa variabel-variabel yang dirumuskan dalam model teoritik penelitian mempunyai hubungan linear secara nyata. Asumsi kelinearan variabel X terhadap Y. Pengujian linearitas dalam hal ini disebut juga uji Tuna Cocok atau uji F. statistik uji hipotesis tersebut adalah $F_{\text {hitung, dimana }}$ $\mathrm{F}_{\text {hitung }}$ diperoleh dari kuadrat Tuna Cocok dibagi dengan kudrat tengah galat murni pada ANOVA. $\mathrm{H}_{\mathrm{o}}$ akan diterima jika nilai $\mathrm{F}_{\text {hitung }}<\mathrm{F}_{\text {tabel }}$, dan $\mathrm{H}_{\mathrm{o}}$ akan ditolak jika nilai $\mathrm{F}_{\text {hitung }}>\mathrm{F}_{\text {tabel }}$ (pada taraf signifikansi 5\%).

\begin{tabular}{|c|c|c|c|c|c|c|c|}
\hline \multicolumn{8}{|c|}{ Tabel Anava } \\
\hline $\begin{array}{l}\text { Sumber } \\
\text { Variabel }\end{array}$ & $\mathrm{db}$ & $\mathrm{JK}$ & RJK & $F_{\text {hitung }}$ & $\begin{array}{c}\mathrm{F}_{\text {tabel }} \\
\alpha \\
0.05\end{array}$ & $\begin{array}{c}\mathbf{F}_{\text {tabel }} \\
\alpha \\
\mathbf{0 . 0 1}\end{array}$ & Ket. \\
\hline total & 124 & 2178430 & & & & & \\
\hline $\begin{array}{l}\text { Koefisien } \\
\text { (a) }\end{array}$ & 1 & 2175385 & 2175385 & & & & \\
\hline $\begin{array}{l}\text { Regresi } \\
\text { (b/a) }\end{array}$ & 1 & 383.590 & 383.590 & 17.5858 & 3.91 & 8.83 & $\begin{array}{c}\text { Sangat } \\
\text { signfikan }\end{array}$ \\
\hline Sisa & 122 & 2661.1 & 21.81 & & & & \\
\hline $\begin{array}{l}\text { Tuna } \\
\text { Cocok }\end{array}$ & 32 & 784.9 & 24.53 & 1.177 & 1.56 & 1.81 & Linear \\
\hline Galat & 90 & 1876.2 & 20.85 & & & & \\
\hline
\end{tabular}

Pengujian Hipotesis

Hubungan Gaya Kepemimpinan (X) dengan Akuntabilitas Kepala Madrasah Aliayah Negeri (Y)

Hasil Perhitungan hubungan X terhadap Y

\begin{tabular}{|c|c|c|c|c|c|c|}
\hline \multirow{2}{*}{$\mathbf{r}_{\mathrm{xy}}$} & \multirow{2}{*}{$\mathbf{r}^{2}{ }_{\mathrm{xy}}$} & \multirow{2}{*}{$\mathrm{dk}$} & \multirow{2}{*}{$\mathbf{t}_{\text {hitung }}$} & \multicolumn{2}{|c|}{$\mathrm{t}_{\text {tabel }}$} & \multirow{2}{*}{ Kesimpulan } \\
\cline { 5 - 6 } & & & & 0,05 & 0,01 & \\
\hline 0,35 & 0,1225 & 34 & 4,63 & 2,358 & 2,275 & Hipotesis diterima \\
\hline
\end{tabular}


Berdasarkan kriteria tersebut ternyata nilai $t_{\text {hitung }}(4,63)>t_{\text {tabel }}$ (2,358), sehingga $\mathrm{H}_{0}$ ditolak dan $\mathrm{H}_{1}$ diterima. Ini berarti bahwa hipotesis penelitian yang menyatakan Gaya Kepemimpinan (X) memiliki hubungan positif dan signifikan dengan Akuntabilitas Kepala Madrasah (Y) dapat diterima karena teruji kebenarannya. Perhitungan secara manual mendapatkan angka yang sama dengan perhitungan menggunakan bantuan SPSS ver.23 dapat dilihat pada tabel berikut:

Tabel Output SPSS

Correlations

\begin{tabular}{|c|c|c|c|}
\hline & & $\begin{array}{c}\text { X_Gaya } \\
\text { Kepemimpinan }\end{array}$ & \begin{tabular}{|c|} 
Y_Akuntabilitas \\
Kepala Madrasah
\end{tabular} \\
\hline \multirow{5}{*}{$\begin{array}{l}\text { X1_Gaya } \\
\text { Kepemimpinan }\end{array}$} & $\begin{array}{l}\text { Pearson } \\
\text { Correlation }\end{array}$ & 1 & $.354^{* *}$ \\
\hline & Sig. (2-tailed) & & .000 \\
\hline & $\begin{array}{l}\text { Sum of Squares } \\
\text { and Cross- } \\
\text { products }\end{array}$ & 5716.927 & 1475.355 \\
\hline & Covariance & 46.479 & 11.995 \\
\hline & $\mathrm{N}$ & 124 & 124 \\
\hline \multirow{5}{*}{$\begin{array}{l}\text { Y_Akuntabilitas } \\
\text { Kepala Madrasah }\end{array}$} & $\begin{array}{l}\text { Pearson } \\
\text { Correlation }\end{array}$ & $.354^{* * *}$ & \\
\hline & Sig. (2-tailed) & .000 & \\
\hline & $\begin{array}{l}\text { Sum of Squares } \\
\text { and Cross- } \\
\text { products }\end{array}$ & 1475.355 & 3044.710 \\
\hline & Covariance & 11.995 & 24.754 \\
\hline & $\mathrm{N}$ & 124 & 124 \\
\hline
\end{tabular}

**. Correlation is significant at the 0.01 level (2-tailed).

Pada tabel di atas hasil $r 41=0,354^{24}$, Kedua hasil perhitungan baik secara manual maupun menggunakan bantuan program SPSS

${ }^{24}$ Ibid. 
versi 23, menunjukkan nilai koefisen jalur yang sama yaitu $r 41=0,354$. Sedangkan untuk menyatakan besar kecilnya kontribusi (sumbangan) variabel Gaya kepemimpinan (X) terhadap Akuntabilitas Kepala Madrasah (Y) yaitu dengan menentukan koefisien determinasi sebagai berikut:

$$
\begin{aligned}
K P & =r^{2} \times 100 \% \\
K P & =0,35^{2} \times 100 \% \\
& =0,1225 \times 100 \%=12,25 \%
\end{aligned}
$$

Bedasarkan hasil perhitungan di atas, besarnya hubungan Gaya kepemimpinan (X) dengan Akuntabilitas Kepala Madrasah (Y) sebesar $12,25 \%$, sedangkan sisanya sebesar $87,75 \%$ dipengaruhi oleh variabel lain.

Berdasarkan hasil pengujian hipotesis, diperoleh koefisien korelasi yang signifikan antara gaya kepemimpinan dengan akuntabilitas kepala MAN, yaitu $r_{Y . X}$ sebesar 0,35. Berdasarkan hasil perhitungan diperoleh koefisien determinan atau hubungan antara gaya kepemimpinan dengan akuntabilitas kepala Madrasah Aliyah Negeri sebesar 0,1225. Jadi gaya kepemimpinan memiliki korelasi positif dengan akuntabilitas kepala Madrasah Aliyah Negeri, yang mana 12,25\% akuntabilitas kepala MAN ditentukan langsung oleh gaya kepemimpinannya. Hal ini mengindikasikan bahwa gaya kepemimpinan kepala madrasah merupakan unsur dalam organisasi pendidikan, untuk menjalin hubungan antara pemimpin dengan bawahannya maupun pihak lain guna mewujudkan kerja sama yang baik dalam mewujudkan tujuan organisasi pedidikan tersebut. Ketika hubungan sudah terjalin dengan baik dan harmonis maka akan tercipta pertanggungjawaban yang tinggi. Sehingga semua aktifitas ditunjukkan dengan transparan dalam rangka mewujudkan akuntabilitas.

Kepemimpinan pendidikan Islam harus berbeda dengan kepemimpinan pendidikan yang lain. Letak perbedaannya adalah terdapat pada pengambilan konsep kepemimpinan yang didasarkan pada Alquran dan Hadis yang diintegrasikan dengan teori-teori kepemimpinan yang sudah berkembang di lembaga-lembaga pendidikan Islam. Menurut Nur Efendi kepemimpinan pendidikan 
Islam dapat dibangun dengan terlebih dahulu harus memahami ayatayat kauniyyah dan qauliyyah. Hasil dari ijtihad yang dilakukan kemudian dikonsultasikan dan dibreak down kepada kegiatan eksperimen yang pada gilirannya melahirkan teori kepemimpinan pendidikan Islam. ${ }^{25}$

Menurut Maisah, 26 superioritas kepemimpinan lembaga pendidikan Islam adalah kepemimpinan yang memiliki tanggung jawab dan mampu menggerakkan organisasi yang dipimpinnya untuk bersaing dengan lembaga pendidikan lain. Adapun tipe kepemimpinan lembaga pendidikan Islam yaitu:
a. Berperilaku jujur (siddiq)
b. Dapat dipercaya (amanah)
c. Menyampaikan segala informasi (tabligh)
d. Cerdas (fatanah)
e. Ikhlas
f. Sabar
g. Rendah hati (tawadu')
h. Adil
i. Mampu mengendalikan diri.

Sedangkan menurut Martinis ${ }^{27}$, menjelaskan bahwa akuntabilitas menyangkut dua dimensi, yakni akuntabilitas vertikal dan akuntabilitas horizontal. Akuntabilitas vertikal menyangkut hubungan antara pengelola sekolah dengan masyarakat, sekolah dan orang tua siswa, sekolah dan instansi di atasnya atau dinas pendidikan. Sedangkan akuntabilitas horizontal menyangkut hubungan antara sesama warga sekolah, antara kepala sekolah dengan komite dan antara kepala sekolah dengan guru. Akuntabilitas tidak saja menyangkut proses pembelajaran, tetapi juga menyangkut pengelolaan keuangan dan kualitas output.

${ }^{25}$ Nur Efendi, Islamic Educational, h. 22-23.

${ }^{26}$ Maisah, Manajemen Strategik dalam Perspektif Pendidikan Islam (Jambi: Salim Media Indonesia, 2016), h. 64.

${ }^{27}$ Martinis Yamin dan Maisah, Standarisasi Kinerja Guru. (Jakarta: GP Press, 2010), h. 40. 
Dari pendapat di atas dapat disimpulkan bahwa kepala sekolah yang akuntabel dalam perspektif Islam adalah kepala sekolah yang melaksanakan sifat-sifat rasul. Kepala madrasah yang akuntabel adalah kepala madrasah yang memiliki kompetensi untuk menciptakan madrasah yang bermutu dan efektif. Ini menggambarkan bahwa kepala madrasah memiliki kekuatan teknikal penerapan fungsifungsi manajemen.

Gaya kepemimpinan kepala madrasah dalam konteks penelitian ini adalah gaya kepemimpinan demokratis. Gaya kepemimpinan demokratis sesuai dengan keadaan tingkat kematangan guru dan staf, yang dapat dilihat dari dua dimensi, yakni dimensi kemampuan (kesadaran dan pemahaman) dan dimensi kemauan (tanggung jawab, kepedulian, dan komitmen).

\section{PENUTUP}

Berdasarkan analisis hasil penelitian dan pembahasan yang telah diuraikan pada bagian sebelumnya, maka penelitian ini menghasilkan kesimpulan bahwa gaya kepemimpinan berkorelasi langsung positif dan signifikan pada kategori rendah terhadap akuntabilitas kepala Madrasah Aliyah Negeri di Provinsi Jambi. Hal ini menunjukkan bahwa semakin tinggi atau semakin baik gaya kepemimpinan seorang kepala madrasah, maka akan semakin tinggi akuntabilitasnya.

Implikasi yang diberikan dari hasil penelitian ini adalah bahwa gaya kepemimpinan berkorelasi langsung terhadap akuntabilitas kepala madrasah. Artinya gaya kepemimpinan yang dimiliki oleh kepala Madrasah Aliyah Negeri akan berpengaruh terhadap akuntabilitas atau pertanggungjawaban dari kepemimpinannya. Implikasinya adalah akuntabilitas kepala Madrasah Aliyah Negeri di provinsi Jambi dapat ditingkatkan dengan memperbaiki gaya kepemimpinannya. Upaya yang dapat dilakukan untuk memperbaiki gaya kepemimpinan agar berdampak pada akuntabilitas adalah dengan mengetahui situasi dan kondisi yang dipimpinnya. Dan tentunya harus selalu ingat kepada janji Allah Swt, bahwa semua perbuatan manusia sebesar biji dzarrah, baik itu meliputi perbuatan 
baik maupun perbuatan tidak baik akan dipertanggungjawabkan di hadapan-Nya kelak.

Kepala Madrasah Aliyah Negeri harus menciptkan gaya kepemimpinan yang dan dapat memberikan pengaruh terhadap yang dipimpin. Gaya kepemimpinan yang didambakan oleh setiap yang dipimpin adalah gaya kepemimpinan yang penuh dengan rasa kasih sayang, jujur, adil dan berintegritas. Permendiknas Nomor. 13 Tahun 2007 menjelaskan tentang standar kepala sekolah/madrasah dalam bidang kompetensi yaitu: kompetensi kepribadian, kompetensi manajerial, kompetensi kewirausahaan, kompetensi supervisi dan kompetensi sosial.

\section{Daftar Pustaka}

Agus Wibowo, Akuntabilitas Pendidikan; Upaya Meningkatkan Mutu dan Citra Sekolah. Yogyakarta: Pustaka Pelajar, 2013.

Departemen Agama RI, Akuntabilitas dan Good Governance. Jakarta: Sekretariat Jenderal Biro organisasi dan tatalaksana, 2006.

Departemen Agama RI, Mushaf Al-Qur'an dan Terjemahnya. Jakarta: AlHuda, 2005.

Fatah Syukur, Manajemen Pendidikan Berbasis pada Madrasah. Semarang: Pustaka Rizki Putra, 2011.

http://disdik.jambiprov.go.id/web/tampil/opini/detail/3.

Ibn Katsir, Tafsir Ibnu Katsir, terjemahan Abdullah bin Muhammad bin Abdurrahman bin Ishaq al-Sheikh. Bogor: Pustaka Imam Syafi'i.

Imam Abdul Fida Isma'il Ibnu Kasit Ad-Dimasyqi, Tafsir Ibnu Katsir, terjemahan. Bahrun Abu Bakar. Bandung: Sinar Baru Algesindo, 2009.

Kasi Kelembagaan dan Sistem Informasi Madrasah Bidang pendidikan Madrasah, Laporan Data Madrasah. Jambi: Kanwil Kementerian Agama Provinsi Jambi, 2013. 
Kementerian Agama RI, Qur'an Asy-Syifaa' Hafalan Terjemah dan Tajwid Berwarna Metode Tikrar. Bandung: Sigma Examedia Arkaleema, 2018.

Maisah, Manajemen Strategik dalam Perspektif Pendidikan Islam. Jambi: Salim Media Indonesia, 2016.

Martinis Yamin dan Maisah, Standarisasi Kinerja Guru. Jakarta: GP Press, 2010.

Mc. Adams, D., et.al. Urban school district accountability systems. U.S: Center for Reform of School Systems under a grant from the U.S. Department of Education, 2003.

Nur Efendi, Islamic Educational Leadership; Memahami Integrasi Konsep Kepemimpinan di Lembaga Pendidikan Islam. Yogyakarta: Kalimedia, 2015.

Peter G. Northouse, Kepemimpinan; Teori dan Praktik. Edisi Keenam, terj. Ati Cahayani. Jakarta: Indeks, 2013.

Riduwan, Skala Pengukuran Variabel-variabel Penelitian. Bandung: Alfabeta, 2013.

Saefullah, Manajemen Pendidikan Islam. Bandung: Pustaka Setia, 2012.

Suwatno dan Donni Juni Priansa, Manajemen SDM dalam Organisasi Publikasi dan Bisnis. Bandung: Alfabeta, 2013.

Syofian Siregar, Metode Penelitian Kuantitatif: Dilengkapi dengan Perhitungan Manual \& SPSS. Jakarta: Kencana, 2013.

Tim Redaksi FOKUSMEDIA, Himpunan Peraturan Perundang-undangan Tentang Sistem Pendidikan Nasional. Bandung: Fokusmedia, 2006.

Tukiran Taniredja dan Hidayati Mustafidah, Penelitian Kuantitatif (Sebuah Pngantar). Bandung: Alfabeta, 2012.

Veithzal Rivai, Bachtiar dan Boy Rafly Amar, Pemimpin dan kepemimpinan dalam Organisasi. Jakarta: Raja Grafindo Persada, 2013. 
Sugeng Kurniawan

Wirawan, Kepemimpinan: Teori, Psikologi, Perilaku Organisasi, Aplikasi dan Penelitian. Jakarta: Raja Grafindo Persada, 2013. 